\title{
Successful Treatment of a Complicated Case of Neuroleptic Malignant Syndrome with a Higher Dose of Bromocriptine and Lorazepam
}

\author{
${ }^{1}$ Ravi Sharma, ${ }^{2}$ Rajesh Kashyap
}

\begin{abstract}
A 53-year-old patient of schizoaffective disorder developed neuroleptic malignant syndrome (NMS) following treatment with haloperidol, clozapine and parenteral fluphenazine. He showed full recovery with immediate discontinuation of potential offenders and prompt treatment with a higher dose of bromocriptine and lorazepam along with management of aspiration pneumonia. Need for early recognition of NMS and treatment by a multidisciplinary team is discussed.
\end{abstract}

Keywords: Neuroleptic malignant syndrome, Bromocriptine, Lorazepam, Fluphenazine, Haloperidol, Clozapine.

How to cite this article: Sharma R, Kashyap R. Successful Treatment of a Complicated Case of Neuroleptic Malignant Syndrome with a Higher Dose of Bromocriptine and Lorazepam. J Postgrad Med Edu Res 2015;49(2):88-90.

Source of support: Nil

Conflict of interest: None

\section{INTRODUCTION}

Neuroleptic malignant syndrome (NMS) is a potentially fatal but rare side effect of neuroleptics. It is characterized by altered consciousness, rigidity, fever, autonomic instability and elevated serum creatinine phosphokinase (CPK) and leukocytosis. ${ }^{1,2}$ Neuroleptic malignant syndrome may lead to hepatic and renal failure, rhabdomyolysis, acute respiratory syndrome and disseminated intravascular coagulation. It is seen in 0.07 to $2.2 \%$ of patients receiving neuroleptics and carries a mortality risk of 10 to $30 \% .{ }^{2}$ Bromocriptine, dantrolene sodium, amantadine and levodopa carbidopa, benzodiazepines and electroconvulsive therapy (ECT) have been shown to be effective in its management. ${ }^{2-5}$ Neuroleptic malignant syndrome may be difficult to diagnose and

\footnotetext{
${ }^{1}$ Professor and Head, ${ }^{2}$ Associate Professor

${ }^{1}$ Department of Psychiatry, Indira Gandhi Medical College and Hospital, Shimla, Himachal Pradesh, India

${ }^{2}$ Department of Medicine, Indira Gandhi Medical College and Hospital, Shimla, Himachal Pradesh, India

Corresponding Author: Ravi Sharma, Professor and Head Department of Psychiatry, Indira Gandhi Medical College and Hospital, Shimla, Himachal Pradesh, India, Phone: 01772883402, e-mail: dr.ravicsharma@gmail.com
}

manage in the presence of serious medical comorbidities like central nervous system (CNS) infections, toxicencephalopathies, agitated delirium, heat stroke, etc. ${ }^{6,7}$ and associated complications, such as acute renal failure, venous thromboemboli, multiple system failure and aspiration pneumonia. ${ }^{8}$ Therefore, it is essential to adopt a multidisciplinary management in such cases. We are reporting a case who developed NMS following addition of fluphenazine to haloperidol and clozapine. This case is primarily reported to highlight the efficacy of early institution of higher dose of bromocriptine and lorazepam and need for multidisciplinary care in averting this potentially fatal condition.

\section{CASE REPORT}

A 53-year-old patient of schizoaffective disorder was admitted in psychiatry ward with acute exacerbation. His symptoms stabilized with haloperidol $10 \mathrm{mg} /$ day, divalproex sodium $1000 \mathrm{mg} /$ day, clozapine $400 \mathrm{mg} /$ day, trihexyphenidyl $4 \mathrm{mg} /$ day and clonazepam $2 \mathrm{mg} /$ day. However, in view of chronic course and poor drug compliance in the past, he was also given two injections of $25 \mathrm{mg}$ fluphenazine decanoate each, after 3 and 4 weeks of admission. He was discharged on above medicines after 4 weeks. About 12 days after discharge, the patient started worsening and was ultimately admitted under medicine with the complaints of altered consciousness, body stiffness, urinary incontinence and loss of appetite.

On examination, patient appeared dehydrated; he was febrile $\left(101.6^{\circ} \mathrm{F}\right)$, diaphoretic, stuporose, had sialorrhea, tremulousness, marked body rigidity, positive Babinski's sign and coarse lung crepitations. His pulse rate was 126 beats/minute, respiratory rate 24 breaths/ minute and blood pressure 100/60 mm Hg. In view of history of psychiatric treatment, a presumptive diagnosis of neuroleptic induced severe extrapyramidal symptoms with aspiration pneumonia was kept along with a rider to rule out meningoencephalitis. All psychotropics except trihexyphenidyl were discontinued, patient was catheterized, I/V line, N/G tube feeding, cold sponging, input-output charting and recording of vital parameters was advised. Cerebral spinal fluid (CSF) 
examination was done and broad spectrum antibiotics and diazepam (5 mg I/V slowly qid) were started. On psychiatric consultation, the author (RCS) kept a strong possibility of NMS with aspiration pneumonia and started bromocriptine $10 \mathrm{mg}$ bid first day then $10 \mathrm{mg}$ tid orally and swapped diazepam with lorazepam $8 \mathrm{mg} /$ day I/V dividedly.

Patient's ECG, CT-head, CSF examination, urinalysis, blood and urine culture were within normal limits but chest X-ray was suggestive of aspiration pneumonia. Complete blood count (CBC) showed marked leukocytosis (WBC-23,300/cmm) with a shift to left (neutrophil count-90\%). Abnormal laboratory parameters included aspartate aminotransferase 501 IU (normal 10-43) and alanine aminotransferase 521 IU (normal 10-30), blood urea nitrogen-77 mg/dl (normal 20-40), serum creat nine1.7/dl (normal 0.5-1.5) and total CPK-1997 IU/1 (normal 24-195). The patient's temperature normalized after 1 week but other parameters kept fluctuating: pulse rate 80 to 126 beats/minute, blood pressure $100 / 60$ to $130 / 90 \mathrm{~mm} \mathrm{Hg}$ and respiratory rate 18 to 24 breaths/minute.

Just after 2 days, patient's sensorium improved, rigidity decreased and he started responding to verbal commands. He cooperated for chest physiotherapy also and over the next 5 days, he became more alert and afebrile and his vital signs stabilized. He showed marked improvement after 15 days and was shifted to psychiatry ward. He started taking orally; bromocriptine and lorazepam were gradually tapered off over next 15 days (total duration 30 days) without any recurrence of psychotic symptoms. The patient was discharged on $4 \mathrm{mg}$ trihexyphenidyl/day after 3 weeks of hospital stay and was maintaining well 1 month after discharge.

\section{DISCUSSION}

Different types of diagnostic criteria have been proposed for diagnosing NMS; however, due to its variable presentation, no single set of criteria is used universally. ${ }^{1,9}$ Levenson's criteria ${ }^{10}$ have been widely cited. It includes three major criteria; fever, rigidity and raised CPK levels and six minor criteria; altered consciousness, diaphoresis, tachypnea, tachycardia, abnormal blood pressure and leukocytosis. For the diagnosis of NMS, presence of all the three major or two major and four minor criteria need to be satisfied. On the basis of history of exposure to neuroleptics, clinical examination and positive Levenson's criteria, a final diagnosis of NMS with aspiration pneumonia was made in our case. Possibility of meningoencephalitis was already ruled out by a negative CSF report.

All the three neuroleptics taken by this patient, i.e. haloperidol, clozapine and fluphenazine are known to cause NMS, ${ }^{1,6,11,12}$ furthermore, propensity for NMS rises with neuroleptic polypharmacy. ${ }^{13,14}$ Therefore, this may be a possible reason for developing NMS in the present case. However, as NMS is most often seen with the high potency and depot neuroleptics, such as halo-peridol and fluphenazine, ${ }^{1,6,12,15}$ it is more likely that these two drugs must have lead to the development of NMS in this case. In our patient, in addition to dehydration, administration of another depot injection of fluphenazine just after 7 days of the first, might have contributed more or compounded the risk for NMS with haloperidol by way of massive dopaminergic receptor antagonism because, NMS is known to result from deficient compensatory mechanisms following blockade of dopaminergic regulation of muscle tone and autonomic function. ${ }^{16-18}$

Bromocriptine (2.5-5 mg 8 hourly per orally or by nasogastric tube) has been listed under 1st line intervention for the treatment of moderate to severe NMS spectrum-related symptoms. ${ }^{19}$ It has been recommended that bromocriptine should be instituted with a starting dose of $2.5 \mathrm{mg} 2$ to 3 times a day, which can be increased to a total daily dose of $45 \mathrm{mg}$ if needed. ${ }^{6}$ In view of the severity of NMS on the very first day, we had started with bromocriptine $10 \mathrm{mg}$ bid which is a relatively higher than recommended starting dose for bromocriptine and increased it to $10 \mathrm{mg}$ tid on the 2 nd day. Bromocriptine can worsen psychosis and hypotension and may precipitate vomiting, and thus should be avoided in patients with risk of aspiration. Premature discontinuation of bromocriptine should be avoided as it can result in rebound symptoms in some cases. ${ }^{6}$

Rapid development of NMS symptoms, quick response and full recovery with bromocriptine which enhanced dopamine transmission and lorazepam which reduced muscle rigidity is noteworthy and is in line with similar reports. ${ }^{3,20-22}$

Neuroleptic malignant syndrome is a potentially lethal side effect of neuroleptic drugs regardless of their duration or dose. ${ }^{9}$ The mortality and morbidity associated with NMS can be decreased significantly if the offending agents are stopped immediately; drugs like bromocriptine and lorazepam are instituted early and in high tolerable doses along with careful screening and management of complications by a multidisciplinary team.

\section{REFERENCES}

1. Chandran GJ, Mikler JR, Keegan DL. Neuroleptic malignant syndrome: case report and discussion. CMAJ 2003;169(5): 439-442.

2. Adnet P, Lestavel P, Krivosic-Horber R. Neuroleptic malignant syndrome. Br J Anaesth 2000;85(1):129-135.

3. Yacoub A, Francis A. Neuroleptic malignant syndrome induced by atypical neuroleptics and responsive to lorazepam. Neuropsychiatr Dis Treat 2006;2(2):235-240. 
4. Troller JN, Sachdev PS. Electroconvulsive treatment of neuroleptic malignant syndrome: a review and report of cases. Aust NZ J Psychiatry 1999;33(5):650-659.

5. Sharma RC, Thakur S, Sharma V. The neuroleptic malignant syndrome: report of three cases. Ind J Psychiatry 1996;38(2): 100-103.

6. Strawn JR, Keck PE Jr, Caroff SN. Neuroleptic malignant syndrome. Am J Psychiatry 2007;164(6):870-876.

7. Kosehasanogullari SG, Akdede B, Akvardar Y, Akan M, Tunca Z. Neuroleptic malignant syndrome caused by combination of risperidone and lithium in a patient with multiple medical comorbidities. Prog Neuropsychopharmacol Biol Psychiatry 2007;31(5):1147-1148.

8. Bhanushali MJ, Tuite PJ. The evaluation and management of patients with neuroleptic malignant syndrome. Neurol Clin 2004;22(2):389-411.

9. Picard LS, Lindsay S, Strawn JR, Kaneria RM, Patel NC, Keck PE Jr. Atypical neuroleptic malignant syndrome: diagnostic controversies and considerations. Pharmacotherapy 2008; 28(4):530-535.

10. Levenson JL. Neuroleptic malignant syndrome. Am J Psychiatry 1985;142(10):1137-1145.

11. Erol A, Putgül G, Sert E, Mete L. Clozapine associated neuroleptic malignant syndrome followed by catatonia: a case report. Turk Psikiyatri Dergisi 2013;24(4):140-144.

12. Seitz DP, Gill SS. Neuroleptic malignant syndrome complicating antipsychotic treatment of delirium or agitation in medical and surgical patients: case reports and a review of the literature. Psychosomatics 2009;50(1):8-15.

13. Buckley PF, Hutchinson M. Neuroleptic malignant syndrome. J Neurol Neurosurg Psychiatry 1995;58(3):271-273.

14. Keck PE Jr, Pope HG Jr, Cohen BM, McElroy SL, Nierenberg AA. Risk factors for neuroleptic malignant syndrome: a casecontrol study. Arch Gen Psychiatry 1989;46(10):914-918.

15. Aruna AS, Murungi JH. Fluphenazine-induced neuroleptic malignant syndrome in a schizophrenic patient. Ann Pharmacother 2005;39(6):1131-1135.

16. Pearlman CA. Neuroleptic malignant syndrome: a review of the literature. J Clin Psychopharmacol 1986;6(5):257-273.

17. Mann SC, Caroff SN, Fricchione G, Campbell EC. Central dopamine hypoactivity and the pathogenesis of the neuroleptic malignant syndrome. Psychiatr Ann 2000;30(5):363-374.

18. Myers RD. Neurochemistry of thermoregulation: two negatives make a positive. Brain Res Bull 1999;50(5,6):453-454.

19. Woodbury MM, Woodbury MA. Neuroleptic-induced catatonia as a stage in the progression toward neuroleptic malignant syndrome. J Am Acad Child Adolesc Psychiatry 1992;31(6):1161-1164.

20. Caroff SN. The neuroleptic malignant syndrome. J Clin Psychiatr 1980;41(3):79-83.

21. Mueller PS, Vester JW, Fermaglich J. Neuroleptic malignant syndrome: successful treatment with bromocriptine. J Amer Med Assoc 1983;249(3):386-388.

22. Patkar AA, Shah LP. Neuroleptic malignant syndrome: a case report. J Postgrad Med 1991;37(3):168-170. 